\title{
O GÊNERO DIPLAZIUM SW. (DRYOPTERIDACEAE, PTERIDOPHYTA) NO ESTADO DO PARANÁ, BRASIL ${ }^{1}$
}

\author{
Jovita Cislinski ${ }^{2}$
}

Recebido em 02.03.95. Aceito em 30.01.96.

\begin{abstract}
RESUMO - (O gênero Diplazium Sw. (Dryopteridaceae, Pteridophyta) no Estado do Paraná, Brasil). O presente trabalho trata do levantamento do gênero Diplazium Sw. (Dryopteridaceae) no Estado do Paraná. A delimitação das espécies foi baseada em caracteres morfológicos. De acordo com os dados obtidos, foi possível reconhecer 11 espécies. Chave de identificação, comentários, distribuição geográfica e ilustrações são apresentados.
\end{abstract}

Palavras-chave: Florística, Diplazium, Dryopteridaceae, Paraná.

\begin{abstract}
The genus Diplazium Sw. (Dryopteridaceae, Pteridophyta) in the State of Paraná, Brasil). The present research is a survey of the genus Diplazium Sw. (Dryopteridaceae) in the Paraná State. The delimitation of the species was based on morphological characters and it was possible to recognize 11 species with the obtained data. Identification Key for the species, descriptions, comments, geographycal distribution and illustrations are presented.
\end{abstract}

Key words: Floristic survey, Diplazium, Dryopteridaceae, Paraná.

\section{Introdução}

O Estado do Paraná é formado por escarpas de estratos de planaltos que declinam suavemente para as direções oeste e noroeste, dividindo a superfície do Estado em duas grandes regiões naturais: o litoral e os planaltos de interior. Estas são ainda subdivididas em cinco subregiões distintas: Litoral, Serra do Mar, $1 .^{\circ}$ Planalto (Curitiba), 2. ${ }^{\circ}$ Planalto (Ponta Grossa) e $3{ }^{\circ}$ Planalto (Guarapuava) (Maack 1981).

A Serra do Mar e a transição entre os planaltos do Estado do Paraná são regiões serranas, com vales e ravinas, apresentando matas primárias e secundárias. Segundo Tryon \& Tryon (1982), existem quatro regiões com alta diversidade de espécies e em cada uma delas, ca. de $40 \%$ são endêmicas. Um desses centros localiza-se nas regiões

\footnotetext{
${ }^{1}$ - Trabalho apresentado no XLV Congresso Nacional de Botânica, São Leopoldo, RS. Parte da Dissertação de Mestrado - UFPR, sob orientação do Prof. Dr. Jefferson Prado.

2 - Bolsista do CNPq. Proc. n. ${ }^{\circ}$ 130572/91-8.Universidade Estadual de Maringá. Dept ${ }^{\circ}$ de Biologia. Av. Colombo, 5790 - Jardim Universitário, Maringá, PR. CEP 87020-900.
} 
Sudeste e Sul do Brasil (Minas Gerais, Espírito Santo até Rio Grande do Sul), especialmente na Serra do Mar (Mata Atlântica).

No que diz respeito à flora pteridofítica do Paraná, as informações são escassas e as referências são apenas listagens. Angely (1963) traz uma lista de pteridófitas com 13 famílias, 49 gêneros e 304 espécies, e Dombrowski (1972) lista 11 famílias, 40 gêneros e 231 espécies.

O presente trabalho representa uma contribuição para o conhecimento do gênero Diplazium Sw. no Estado do Paraná e conseqüentemente para a complementação da flora pteridofítica da Região Sul do Brasil.

\section{Material e métodos}

As coletas foram realizadas entre 1992 e meados de junho de 1993, num total de 27 viagens, tomando-se como ponto de partida os locais indicados nas etiquetas das exsicatas analisadas previamente, com acréscimo de outras estações de coleta (Figura 1).

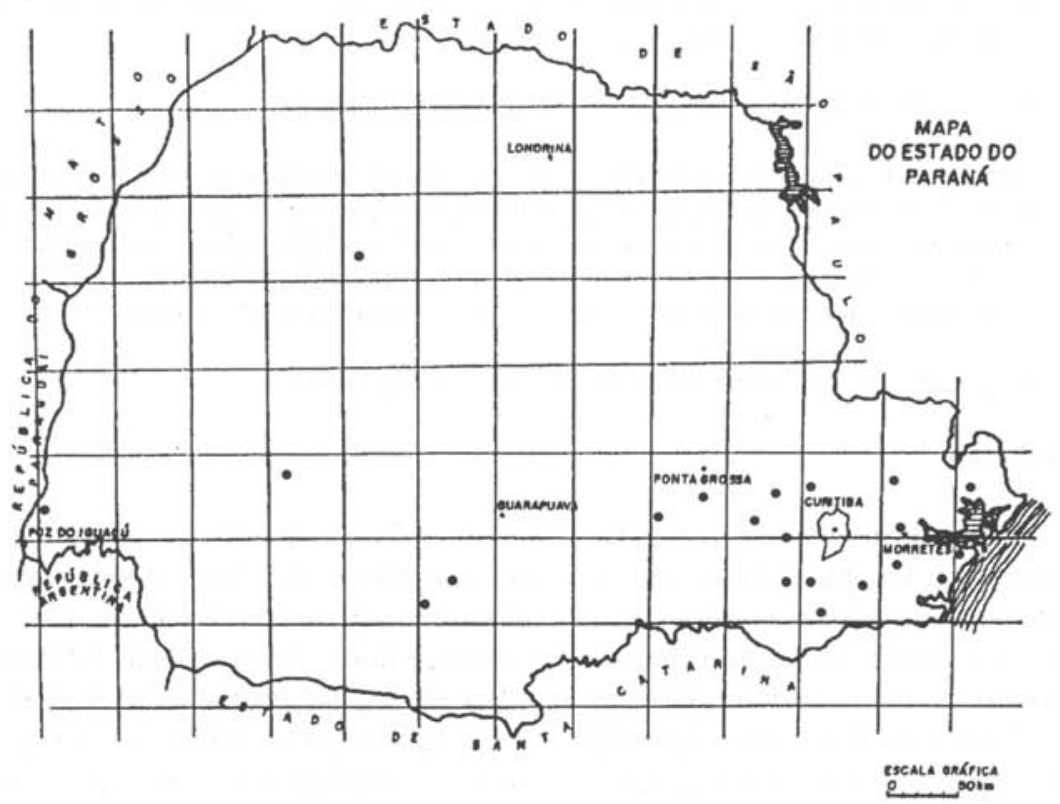

Figura 1. Mapa do Estado do Paraná com os pontos de coleta.

O material foi preparado segundo as técnicas descritas por Radford et al. (1974) e encontra-se depositado no Herbário do Dept ${ }^{\circ}$ de Botânica da UFPR (UPCB), com algumas duplicatas distribuídas aos Herbários MBM, RB e SP. 
A descrição das espécies foi baseada no exame dos materiais coletados no Estado do Paraná. Foram analisados também exemplares herborizados de outros estados do país, cujas coleções procederam dos herbários CESJ, GUA, HBR, ICN, MBM, PACA, PKDC, R, RB, SP, SPF e UEC.

Foram analisados caracteres morfológicos vegetativos e reprodutivos. Os espécimes foram identificados, utilizando-se literatura especializada e chaves analíticas dos trabalhos de Baker (1870), Sehnem (1979), Stolze (1981), Proctor (1985) e Tryon \& Stolze (1991). As observaões e comentários sobre a distribuição geográfica, tipo de habitat e a formação vegetal, foram baseadas no material coletado bem como através de observações de campo e informações extraídas das esxicatas adicionais de outros estados, provenientes dos herbários citados acima. No presente trabalho é apresentado apenas uma seleção do material examinado.

O sistema de classificação adotado para a família é o de Tryon \& Tryon (1982). A seqüência de apresentação dos táxons foi baseada na complexidade da dissecção da lâmina, iniciando-se portanto com a lâmina simples seguida de lâmina 1-pinada e por fim lâmina 2-pinada.

\section{Resultados e discussão}

Nos trabalhos de Angely (1963), Dombrowski (1972) e Sehnem (1979), sete espécies do gênero foram mencionadas para o Estado do Paraná. Com o presente levantamento, foram adicionadas quatro espécies a esta lista: Diplazium leptocarpon Fée, D. petersenii (Kze.) Christ, D. rostratum Fée e D. turgidum Ros.

Dryopteridaceae Herter, Rev. Sudam. Bot. 9: 15. 1949.

Gênero - tipo: Dryopteris Adans.

Caule ereto, raramente arborescente, decumbente a longo-reptante, robusto ou não, dictiostélico, esclerificado, com escamas. Frondes variando de $1 \mathrm{~cm}$ a $3 \mathrm{~m}$ compr., inteiras a lobadas, até freqüentemente pinadas, raramente pedadas ou flabeladas, circinada nos brotos; pecíolo sem estípulas, raramente expandido lateralmente; esporângios originam-se em soros abaxiais arredondados ou alongados, receptáculo ao longo da nervura ou no ápice da nervura, elevado ou não, raramente com pedicelo (ou ainda os esporângios recobrem inteiramente a superfície abaxial da lâmina foliar); indúsio peltado, reniforme a alongado, raramente globoso ou ausente; esporângios com pedicelo curto ou longo, com 2-3 células abaixo do ápice, ânulo vertical ou quase e interrompido pelo pedicelo; esporos monoletes, desprovidos de clorofila (raramente com). Gametófito epigeu, clorofilado, mais ou menos obcordado a ligulado, raramente ramificado, levemente a conspicuamente espessado no centro, glabro, às vezes com glândulas unicelulares ou tricomas, estes raramente multicelulares; anterídios e arquegônios nascem na superfície abaxial, geralmente na região central, anterídios tricelulares, separados ou entre os arquegônios.

Segundo Tryon \& Tryon (1982), Dryopteridaceae é uma família ampla e diversificada, com ca. de 50 gêneros, onde 30 são americanos. 
Diplazium Sw., Journ. Bot. (Schrad.) 1800 (2): 61. 1802.

Espécie-tipo: Diplazium plantagineum (L.) Sw. (Asplenium plantagineum L., nom. superf. para Asplenium plantaginifolium L.)= Diplazium plantaginifolium (L.) Urban.

Plantas terrestres, rupestres ou muito raramente epífitas. Rizoma geralmente ereto ou decumbente até longo-reptante, com escamas e geralmente com muitas raízes fibrosas. Frondes monomorfas ou quase, variando de $25 \mathrm{~cm}$ a $3 \mathrm{~m}$ compr., cespitosas ou mais ou menos distantes umas das outras; lâmina simples e inteira até 3-pinadopinatífida, glabra ou levemente pubescente na face abaxial, podendo apresentar ainda escamas esparsas; padrão de venação da lâmina aberto ou anastomosado. Soros alongados, ao longo das nervuras, raramente percorrendo o curso das nervuras anastomosadas, sobre um receptáculo pouco ou levemente proeminente, protegidos por um indúsio ou raramente sem indúsio, sem paráfises; esporos mais ou menos elipsoidais, monoletes, com proeminências (alas), ou de superfície equinada ou papilada.

De acordo com Tryon \& Tryon (1982), Diplazium é um gênero com aproximadamente 300 espécies, que apresenta distribuição pantropical com poucas extensões para regiões subtemperadas.

O gênero está representado no Estado do Paraná por 11 espécies, as quais podem ser distinguidas com base nos caracteres apresentados na seguinte chave:

1a- Lâmina simples, inteira a lobada na base 1.D. plantaginifolium 1b- Lâmina composta.

2a- Lâmina 1-pinada.

3a-Plantas com a lâmina pubescente nas faces abaxial e adaxial, apenas nas partes vasculares 3.D. petersenii

3b-Plantas com a lâmina glabra ou pubescente somente na face abaxial, apenas nas partes vasculares.

4a- Plantas glabras. 2.D. cristatum

4b- Plantas pubescentes apenas nas partes vasculares.

5a- Indumento formado por escamas e 2 tipos de tricomas (tricomas alvos, menores e tricomas castanhos, linearfiliformes, maiores) 4. D. ambiguum

5b- Indumento formado por apenas um tipo de tricoma e/ou escamas.

6a-Escamas do pecíolo com a margem subinteira; raque com tricomas e escamas. 5.D. turgidum

6b- Escamas do pecíolo com a margem denteada; raque apenas com escamas.

7a- Escamas dicromáticas, projeções da margem geralmente bífidas, paredes celulares delgadas ......... 
2b- Lâmina 2-pinada.

7b- Escamas monocromáticas, projeções da margem raramente bífidas, paredes celulares levemente espessadas (subclatradas) 7. D. leptocarpon

8a- Pínulas inteiras, geralmente com a margem lobada (raramente 2pinado-pinatífida); indúsio com a margem inteira......... 4. D. ambiguum 8b- Pínulas pinatífidas a pinatissectas; indúsio com a margem fimbriada ou subinteira.

9a- Pínulas predominantemente pinatissectas; rizoma horizontal, longo-reptante, indumento formado por um tipo de tricoma ....... 9.D. herbaceum

$9 \mathrm{~b}$ - Pínulas pinatífidas; rizoma vertical, subereto a ereto, indumento formado por mais de um tipo de tricoma e/ou escamas. 10a- Indumento da face abaxial da lâmina formado somente por escamas, escamas do pecíolo com paredes delgadas. 11a- Escamas dicromáticas, projeções da margem geralmente bífidas 8.D. rostratum

11 b- Escamas monocromáticas, projeções da margem raramente bífidas 7.D. leptocarpon

10b- Indumento da face abaxial da lâmina formado por tricomas e escamas, escamas do pecíolo com paredes levemente espessadas (subclatradas).

12a- Indumento somente na face abaxial da raque, raquíola e parte das costas, formado por um tipo de tricoma; indúsio com a margem fimbriada 5.D. turgidum

12b- Indumento na face abaxial do tecido laminar, da raque, raquíola e costas, formado por 2 tipos de tricomas (tricomas alvos, menores e tricomas castanhos, linear-filiformes, maiores); indúsio com a margem subinteira

6.D. cf. expansum

\section{Descrição das espécies:}

\section{Diplazium plantaginifolium (L.) Urban, Symb. Antill. 4: 31. 1903.}

Figura: 5-A; 6-A.

Rizoma subereto a ereto, com poucas escamas oval-lanceoladas, variando de castanho-escuras a pretas, monocromáticas ou quase, com a margem irregular para o ápice, formadas por células com paredes delgadas. Frondes 55-70 cm compr., indumento da face abaxial formado por tricomas unisseriados e ramificados, esparsos ao longo da costa e base das nervuras; pecíolo com escamas na base, iguais na forma às do rizoma; lâmina oval-lanceolada a elíptico-lanceolada, simples, inteira ou ocasionalmente lobada na base, com a margem crenulada a raramente lobado-denticulada, 


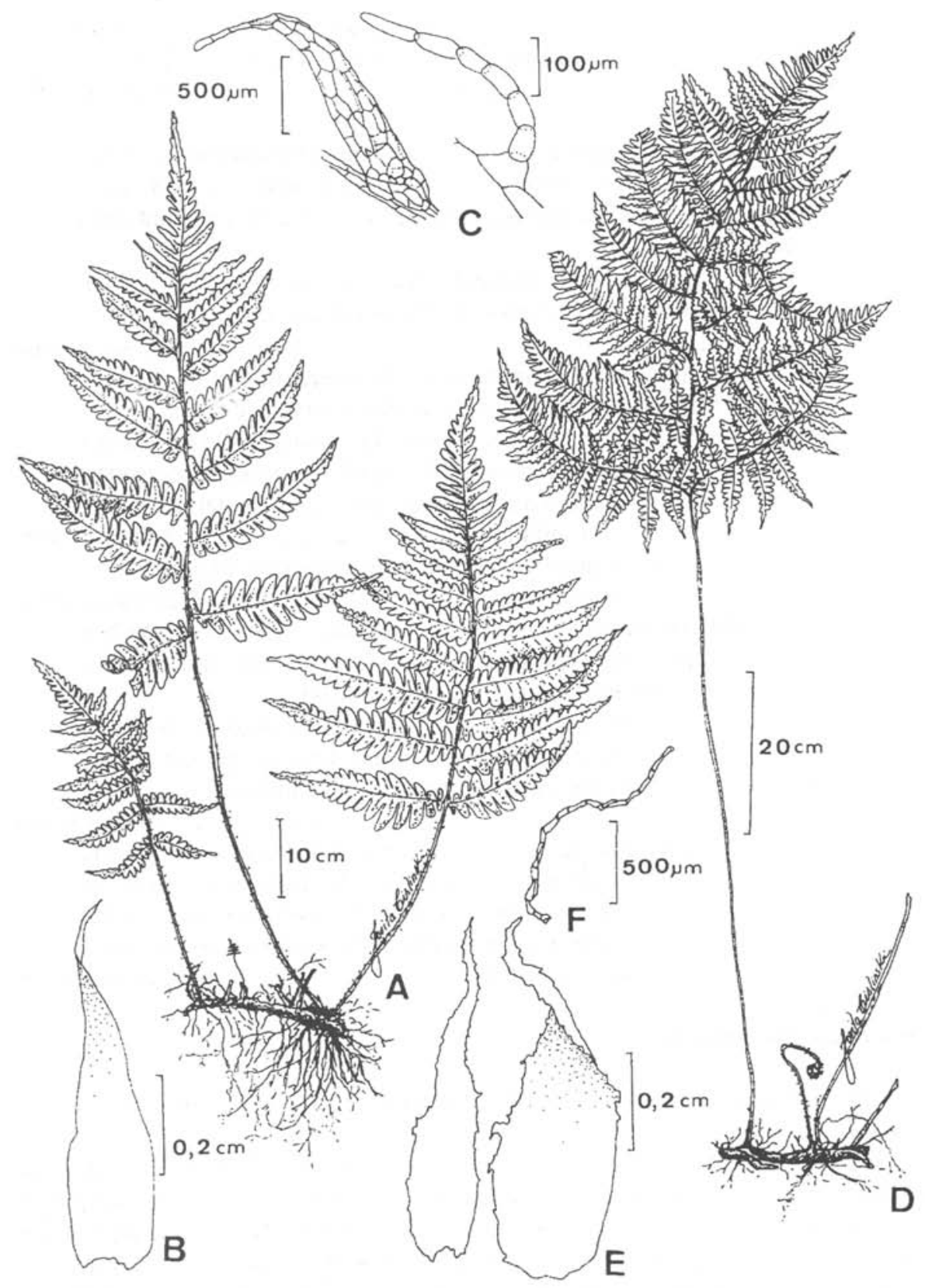

Figura 2. A-C: Diplazium petersenii. A) Hábito; B) Escama da base do pecíolo; C) Indumento das faces abaxial e adaxial da lâmina: escama e tricoma. D-F: D. herbaceum. D) Hábito; E) Escama da base do pecíolo; F) Tricoma da face abaxial da lâmina. 
podendo apresentar gemas vegetativas na base, na face adaxial; nervuras acroscópicas simples, basioscópicas furcadas até 4 vezes. Soros curtos a longos, 0,2-3,0 cm compr.; indúsio de cor castanha, margem inteira.

Material selecionado: Paraná: Guaraqueçaba, Serrinha, 13/IV/1967, G. Hatschbach 16.297 (HBR, MBM, PACA); Paranaguá, Ilha do Mel, 28/XI/1992, J. Cislinski 231 et S. M. Silva (MBM, RB, SP, UPCB).

Diplazium plantaginifolium distingue-se das demais espécies estudadas por apresentar a lâmina simples. Esta espécie exibe certa variabilidade com relação à base, ao ápice e à margem da lâmina, apresentando formas transicionais entre atenuada e truncada para a base, a qual pode ser ainda inteira ou lobada; o ápice é acuminado gradativamente ou abruptamente, às vezes caudado, e a margem varia de crenulada a lobado-denticulada. Foi constatado também a presença de indumento (tricomas unisseriados e ramificados). Tal caráter não foi mencionado na descrição original nem em descrições posteriores.

Com distribuição geográfica consideravelmente ampla, Diplazium plantaginifolium tem sido encontrada de Pernambuco ao Rio Grande do Sul, via Serra do Mar (Mata Atlântica). No Estado do Paraná também foi registrada somente na região de Floresta Atlântica, em encostas de morros, próximo a regatos, entre rochas.

\section{Diplazium cristatum (Desr.) Alston, J. Bot. 74: 173. 1936.}

Figura: 5-B; 6-B.

Rizoma subereto a ereto, com poucas escamas oval-lanceoladas, castanhas, monocromáticas ou quase, com a margem irregular a brevemente denteada para o ápice, formadas por células com paredes delgadas. Frondes $25-100 \mathrm{~cm}$ compr., glabras; pecíolo com poucas escamas na base, iguais na forma às do rizoma; lâmina 1pinado-pinatilobada a 1-pinado-pinatífida; pinas basais e medianas elíptico-lanceoladas, opostas a alternas, com bases inequilaterais, i.e., lobo basal do lado acroscópico mais desenvolvido; nervuras simples, raramente furcadas, com 3-5 (-6) pares por lobo. Soros curvos e geralmente longos, 0,3-1,0 cm compr.; indúsio de cor castanha, margem inteira.

Material selecionado: Paraná: Guaraqueçaba, Fazenda Abobreira, 24/IX/1970, G. Hatschbach 24.754 (MBM, PACA, PKDC); Pinhão, Segredo (UHS), Reserva Rio dos Touros, 12/III/1992, J. Cislinski 101 et J. Prado (UPCB); Foz do Iguaçú, Parque Nacional do Iguaçú, 25/V/1949, A. P. Duarte 1872 et E. Perreira (RB).

Diplazium cristatum caracteriza-se pela base das pinas conspicuamente inequilateral, pela ausência de indumento e pelo indúsio com a margem inteira (Figura 6-B). Apresenta grande variabilidade com relação à dissecção das pinas. Estas podem ser subinteiras, com margem breve a profundamente lobada ou ainda apresentarem-se pinatífidas. A espécie mais próxima é $D$. petersenii (Kze.) Christ, que também apresenta o mesmo padrão de dissecção da lâmina (uma vez pinada), porém, esta apresenta indumento formado por tricomas e escamas em ambas as faces da lâmina e rizoma horizontal. 


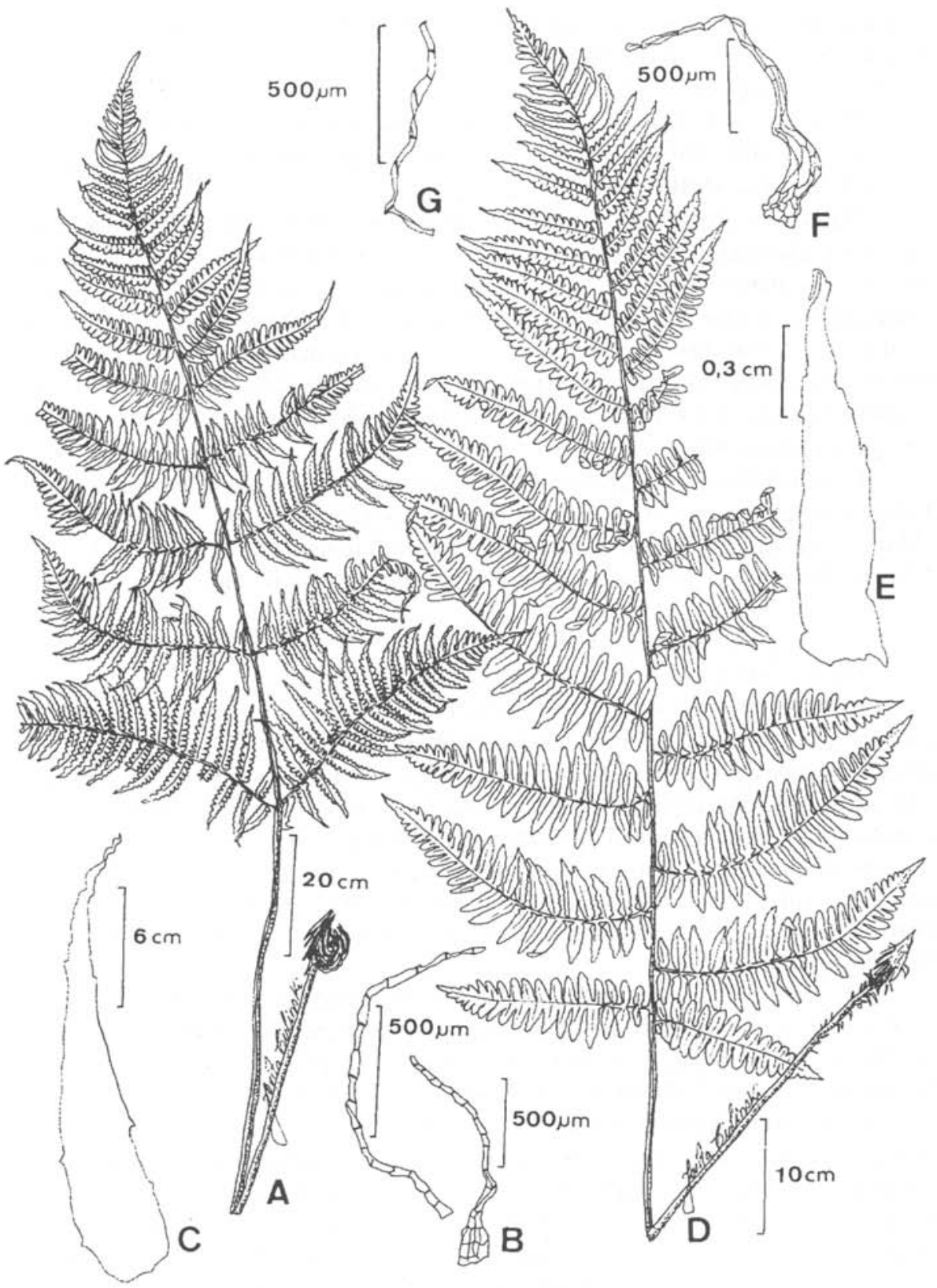

Figura 3. A-C: Diplazium turgidum. A) Hábito; B) Indumento da face abaxial da lâmina: tricoma e escama; C) Escama da base do pecíolo. D-G: D. ambiguum. D) Hábito; E) Escama da base do peciolo; F) Escama da face abaxial da lâmina; G) Tricoma da face abaxial da lâmina. 
Diplazium cristatum ocorre no Brasil principalmente nas regiões Sudeste e Sul, do Espírito Santo ao Rio Grande do Sul, com registros também para os estados do Ceará e Minas Gerais. No Paraná, foi encontrada de oeste a leste, ocorrendo na Floresta Atlântica, Floresta Subtropical, em matas de galeria, às margens de córregos e regatos.

3. Diplazium petersenii (Kze.) Christ, Bull. Ac. Géogr. Bot. Mors.: 245. 1902. Figura: 2-A, B, C; 5-C; 6-C.

Rizoma horizontal, longo-reptante, com muitas raízes fibrosas e com escamas lanceolado-acuminadas, variando de castanho-claras a castanho-escuras, monocromáticas ou quase, com a margem inteira, formadas por células com paredes delgadas. Frondes 41-97 cm compr., pubescentes, indumento em ambas as faces, formado por tricomas e escamas, tricomas articulados, alvos, escamas lanceolado-filiformes, amarelo-claras (esparsas) sobre o pecíolo, raque, costas e cóstulas; pecíolo com escamas na base, iguais na forma às do rizoma; lâmina 1-pinado-pinatífida, com 6-11 pares de pinas; pinas basais e medianas elíptico-lanceoladas, pecioluladas a sésseis, opostas a alternas, inequilaterais a subequilaterais na base; nervuras simples ou furcadas, com 57 pares por segmento. Soros retos e curtos, 0,2-0,3 cm compr.; indúsio castanho-claro, margem fimbriada.

Material selecionado: Paraná: Serra do Mar, São João, Estrada da Graciosa, 23/ XV/1972, L.T. Dombrowski 4.289 et Y.S. Kunioshi 3.471 (PKDC); Mangueirinha, Segredo (UHS), Águas Vigor, 11/III/1992, J. Cislinski 77 et J. Prado (UPCB); Lapa, Butiatuvinha, 13/XII/1992, J. Cislinski 242; R. N. Cislinski; M. L. Nowadski (UPCB).

Diplazium petersenii caracteriza-se pela presença de indumento em ambas as faces da lâmina e pelo rizoma horizontal, longo-reptante. Apresenta certa variabilidade com relação à forma das pinas e segmentos. As pinas apresentam uma série de intermediários entre a forma elíptico-lanceolada e lanceolada. Os segmentos podem se apresentar de tamanhos irregulares (lado acroscópico menor que o lado basioscópico) ou serem iguais (ambos os lados com o mesmo tamanho), além de variarem na forma (subagudos a obtusos) e na margem (crenulada a denteada). Observou-se ainda a presença de tricomas alvos sobre o indúsio (Figura 5-C). É uma espécie asiática introduzida no país e ocorre de forma subespontânea no Estado do Paraná.

Diplazium petersenii é encontrada nas regiões Sul e Sudeste do Brasil, de Minas Gerais ao Rio Grande do Sul. No Paraná, ocorre principalmente na região leste do Estado, sendo encontrada na Floresta Atlântica, Floresta Ombrófila Mista (mata de Araucária), matas-de-galeria e em serras de planaltos, em orlas de matas, barrancos, às margens de rios e arroios.

\section{Diplazium ambiguum Raddi, Opusc. Sci. 3: 292. 1819.}

Figura: 3-D, E, F, G; 5-E; 6-E.

Rizoma vertical, subereto a ereto, com escamas elíptico-lanceoladas, castanhas, monocromáticas ou quase, com a margem inteira a remotamente denteada, formadas por células com paredes delgadas. Frondes 0,6-1,6 m compr., indumento da face abaxial formado por 2 tipos de tricomas e escamas, tricomas alvos, menores, caracte- 


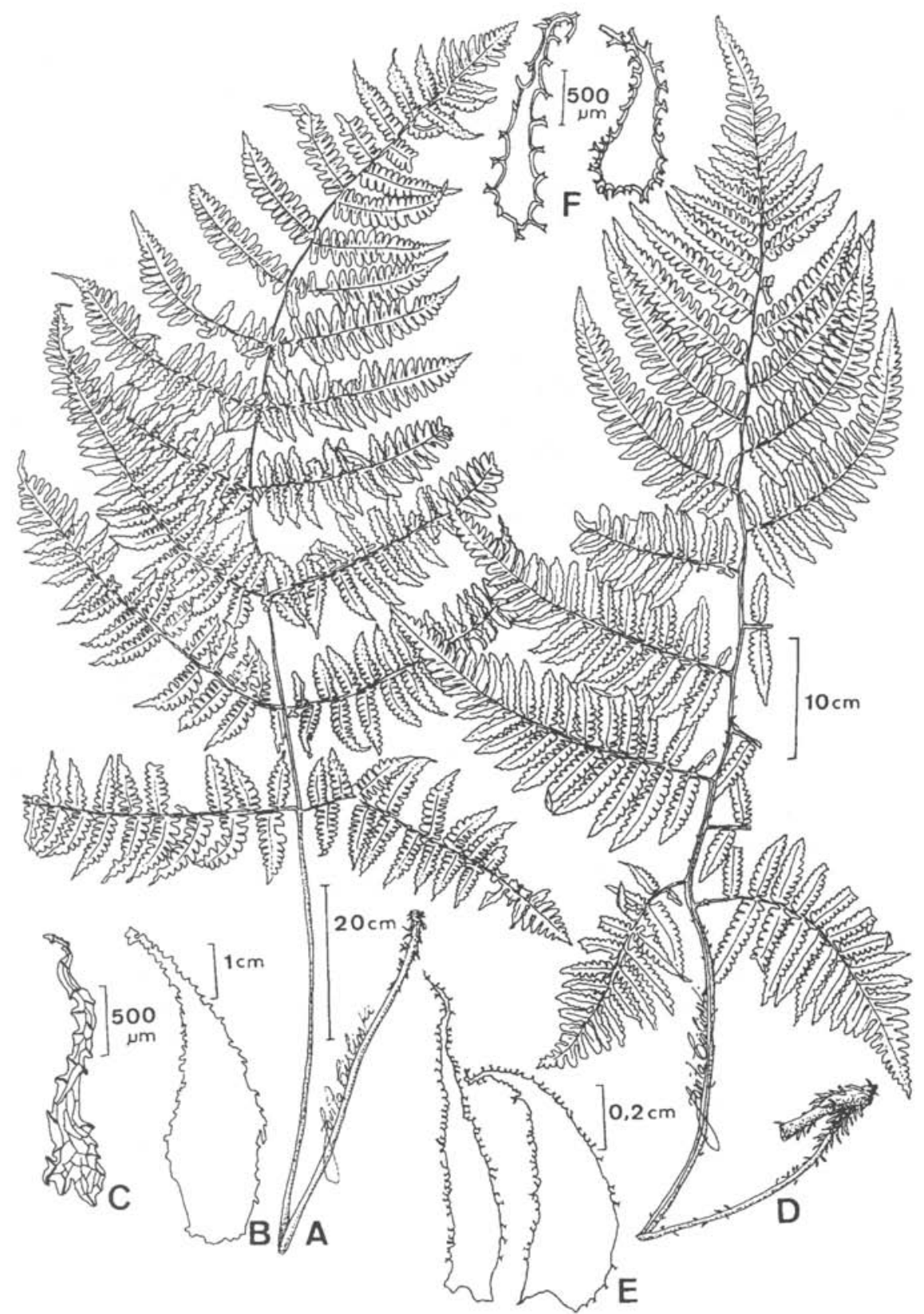

Figura 4. A-C: Diplazium leptocarpon. A) Hábito; B) Escama da base do pecíolo; C) Indumento da face abaxial da lâmina: escama. D-F: D. rostratum. D) Hábito; E) Escamas da base do pecíolo; F) Indumento da face abaxial da lâmina: escamas. 
rizando a pubescência do pecíolo, raque, raquíolas e costas; tricomas articulados, castanhos, esparsos sobre a raque, raquíolas e mais raramente sobre as costas; escamas lanceolado-filiformes esparsas sobre raque e raquíolas; pecíolo com escamas, iguais na forma às do rizoma; lâmina 1-pinado-pinatífida a 2-pinado-pinatilobada, raramente 2-pinado-pinatífida; pinas basais e medianas lanceoladas, pecioluladas, opostas a alternas, subequilaterais, com 5-12 pares de pínulas; pínulas elíptico-lanceoladas, variando de pinatilobadas a pinatífidas, subsésseis a adnatas, opostas a alternas; nervuras simples ou furcadas, 3-4 pares por lobo. Soros retos a ligeiramente curvos, 0,3-0,7 cm compr.; indúsio castanho-claro, margem inteira.

Material selecionado: Paraná: Antonina, Rio Copiuva, 23/VI/1972, G. Hatschbach 29.726 (MBM, PACA); Campina Grande do Sul, BR 116-SP, próx. Barragem Capivari, 20/X/1992, J. Cislinski 202 e 203; R.N. Cislinski; M.L. Nowadski (RB, SP, UPCB).

Diplazium ambiguum caracteriza-se por apresentar as pínulas subsésseis a adnatas para o ápice da pina; pecíolo, raque, raquíolas, costas e nervuras pubescentes na face abaxial; indumento formado por dois tipos de tricomas e escamas (Figura 3F,G), e indúsio com a margem inteira (Figura 6-E). D. ambiguum varia quanto ao padrão de dissecção da lâmina, que pode ser 1-pinado-pinatífida, 2-pinada ou 2pinado-pinatífida. A espécie é similar a $D$. turgidum quanto à dissecção da lâmina, porém, $D$. turgidum apresenta as escamas da base do pecíolo subclatradas e a margem do indúsio fimbriada.

Diplazium ambiguum apresenta distribuição geográfica conhecida nos estados do Rio de Janeiro, São Paulo, Paraná e Santa Catarina. Sehnem (1979) menciona esta espécie também para o Rio Grande do Sul. No Estado do Paraná ocorre principalmente na Floresta Atlântica, crescendo no interior de mata, em locais bastante úmidos, próximo de rios e regatos, entre rochas e próximo à cascatas.

5. Diplazium turgidum Ros., Hedwigia 46: 109. 1907.

Figura: 3-A, B, C; 5-G; 6-F.

Rizoma vertical, ereto, com escamas elíptico-lanceoladas, variando de castanho-escuras a pretas, monocromáticas ou quase, subclatradas, com a margem inteira a remotamente denteada. Frondes 0,50-1,7 m compr., indumento da face abaxial formado por tricomas e escamas, esparsos sobre a raque, raquíola e costas; tricomas articulados, castanhos; escamas lanceolado-filiformes; pecíolo com escamas, iguais na forma às do rizoma; lâmina 1-pinado-pinatífida a 2-pinado-pinatífida, com 8-16 pares de pinas; pinas basais e medianas elíptico-lanceoladas, pecioladas a subsésseis, opostas a alternas, 8-13 pares de pínulas; pínulas lanceoladas, predominantemente pinatífidas, pecioluladas a subsésseis, opostas a alternas; nervuras simples ou furcadas, 3-5 pares por segmento. Soros retos, curtos, 0,2-0,4 cm compr.; indúsio de cor castanha, margem fimbriada.

Material selecionado: Paraná: Campo Largo, Bateias, 10/III/1993, J. Cislinski 254 et al. (UPCB); Campina Grande do Sul, BR-116, Barragem Capivari, 20/VII/ 1992, J. Cislinski 204; R.N. Cislinski; M.L. Nowadski (RB, UPCB); Guaratuba, Km 


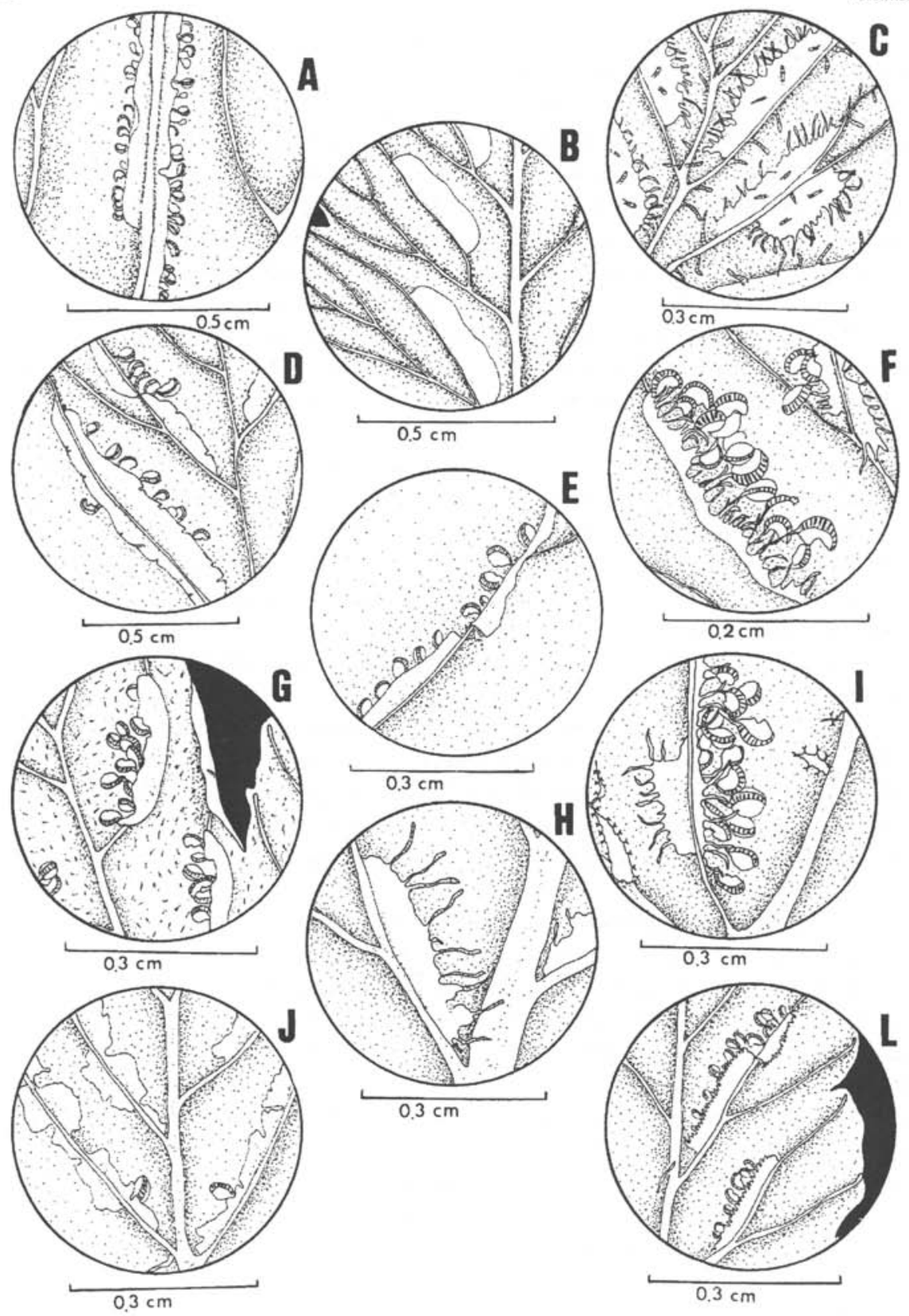

Figura 5. Detalhe da margem das escamas da base do pecíolo das espécies estudadas de Diplazium: A) D. plantaginifolium; B) D. cristatum; C) D. petersenii; D) D. cf. striatum; E) D. ambiguum; F) D. cf. expansum; G) D. turgidum; H) D. leptocarpon; I) D. rostratum; J) Diplazium sp. L) D. herbaceum. 
68 (5 Km antes de Garuva), 20/XII/92, J. Cislinski 252; R. N. Cislinski; M. L. Nowadski (UPCB).

Diplazium turgidum caracteriza-se por apresentar escamas da base do pecíolo subclatradas, indumento da face abaxial formado por tricomas e escamas (Figura 3-B) e pelo indúsio com a margem fimbriada (Figura 6-F). Exibe certo polimorfismo com relação à dissecção da lâmina, que pode ser desde 1-pinado-pinatífida a 2-pinada com pínulas pinatífidas ou com a margem lobada. A espécie mais próxima éD. ambiguum, cujo padrão de dissecção da lâmina é semelhante porém, D. ambiguum apresenta indumento formado por dois tipos de tricomas além de escamas e indúsio com a margem inteira.

Diplazium turgidum apresenta distribuição geográfica conhecida até o presente apenas para os Estados de São Paulo, Paraná e Rio Grande do Sul, no entanto, apesar de não ter sido observado nenhum espécime, a sua ocorrência para Santa Catarina foi registrada por Sehnem (1979). No Paraná, foi encontrada ocorrendo preferencialmente em Floresta Atlântica, podendo ser encontrada ocasionalmente em matas de galeria nas regiões de planalto. Cresce geralmente em orlas de matas, encostas de morros, próximo de riachos ou às margens de regatos, em locais parcialmente ensolarados e úmidos.

6. Diplazium cf. expansum Willd., Sp. Pl. 5: 354. 1810.

Figura: 5-F; 6-G.

Rizoma vertical, subereto a ereto, com escamas elíptico-lanceoladas, variando de castanho-escuras a pretas, monocromáticas ou quase, de margem inteira a raramente denteada, subclatradas. Frondes 1,5-1,7 m compr., glabras na face adaxial e glabrescentes na face abaxial, indumento formado por 2 tipos de tricomas e escamas; tricomas alvos, menores, caracterizando a pubescência da lâmina e tricomas articulados, castanhos; escamas lanceolado-filiformes, ambos esparsos sobre a raque, raquíolas e costas; pecíolo com escamas, iguais na forma às do rizoma; lâmina 2-pinadopinatífida, com 14-20 pares de pinas; pinas basais e medianas elíptico-lanceoladas, pecioluladas, subopostas a alternas, com 14-16 pares de pínulas; pínulas elípticolanceoladas, pecioluladas, opostas a alternas; nervuras simples ou furcadas. Soros retos e curtos, 0,3-0,4 cm compr.; indúsio de cor castanha, margem inteira.

Material selecionado: Paraná: Pinhão, Segredo (UHS), Reseva Rio dos Touros, 12/III/1992, J. Cislinski 102 et J. Prado (UPCB); Campo Largo, Bateias, 10/III/1993, J. Cislinski 265; R.N. Cislinski; M.L. Nowadski (UPCB).

Diplazium cf. expansum caracteriza-se principalmente por apresentar a lâmina pubescente na face abaxial, pelas escamas da base do pecíolo subclatradas e pela margem do indúsio inteira (Figura 6-G). Para Stolze (1981) e Tryon \& Stolze (1991), D. expansum caracteriza-se por apresentar indúsio com a margem erodido-ciliada. Porém, os indivíduos desta espécie encontrados no Estado do Paraná, não apresentaram tal característica, o que ocasionou certa dificuldade na identificação da espécie tomando por base apenas a descrição original, sem a análise do tipo. D. cf. expansum é muito similar à $D$. turgidum quanto à dissecção da lâmina, contudo, esta última 


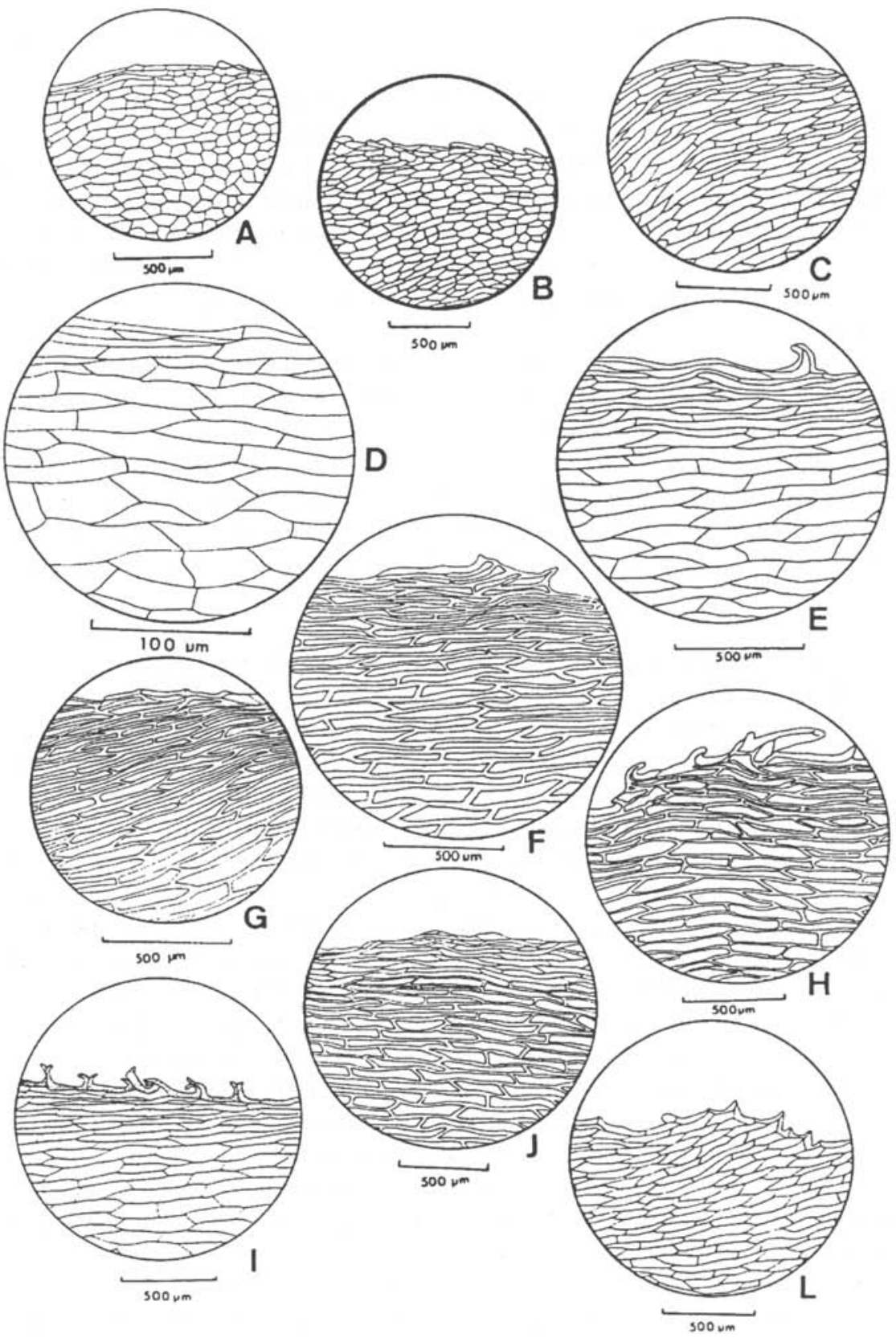

Figura 6. Detalhe da margem do indúsio das espécies estudadas de Diplazium: A) D. plantaginifolium; B) D. cristatum; C) D. petersenii; D) D. cf. striatum; E) D. ambiguum; F) D. turgidum; G) D. cf. expansum; H) D. leptocarpon; I) D. rostratum; J) Diplazium sp.; L) D. herbaceum. 
apresenta indumento formado por apenas um tipo de tricoma e por escamas somente nas partes vasculares, além do indúsio fimbriado.

Diplazium cf. expansum foi encontrado até o presente apenas nos estados de São Paulo, Paraná e Santa Catarina. No Paraná ocorre em vales de regiões serranas, crescendo em locais parcialmente ensolarados, às margens de córregos ou entre rochas.

7. Diplazium leptocarpon Fée, Crypt. Vasc. Brés. 1: 80- 81, t. 23, f.2. 1869. Figura: 4-A, B, C; 5-H; 6-H.

Rizoma vertical, subereto, com escamas elíptico-lanceoladas, castanho-escuras, monocromáticas ou quase, margens denteadas, projeções raramente bífidas, subclatradas. Frondes $63-72 \mathrm{~cm}$ compr., indumento da face abaxial da raque, raquíolas e costas, bem como na base e ao longo de toda a extensão do pecíolo, formado por escamas, iguais às do rizoma, variando apenas na forma, de lanceoladas a lanceoladofiliformes; lâmina 1-pinado-pinatífida a 2-pinado, com 7-12 pares de pinas; pinas basais e medianas elíptico-lanceoladas, pecioluladas a subsésseis, subopostas a alternas, com 7-15 pares de pínulas; pínulas lanceoladas, sésseis a adnatas, com a margem lobada ou pínulas pinatífidas; nervuras simples, 2-4 pares por lobo. Soros retos e curtos, 0,2-0,3 cm compr.; indúsio de cor castanha, margem fimbriada.

Material selecionado: Paraná: Morretes, Estrada da Graciosa, 11/V/1992, J. Cislinski 156 et al. (UPCB); Idem, 14/II/1993, J. Cislinski 256; R.N. Cislinski; M.L. Nowadski (UPCB).

Diplazium leptocarpon caracteriza-se por apresentar o indumento formado por escamas com margens denteadas (projeções raramente bífidas), monocromáticas ou quase, subclatratadas (Figura 4-B,C) e pelo indúsio com a margem fimbriada (Figura 6-H).D. rostratumapresenta padrão de dissecção da lâmina semelhante, porém difere por apresentar escamas dicromáticas com projeções bífidas na margem.

Diplazium leptocarpon é encontrada nos estados de Minas Gerais, Rio de Janeiro, São Paulo e Paraná. De ocorrência rara no Estado do Paraná, a espécie foi encontrada apenas no interior da Floresta Atlântica, próximo a regatos, em locais parcialmente sombreados.

8. Diplazium rostratum Fée, Crypt. Vasc. Brés. 1: 81, t. 24, f. 2.1869.

Diplazium remotum Fée, Crypt. Vasc. Brés. 1: 81, t. 24, f. 1. 1869.

Figura: 4-D, E, F; 5-I; 6-I.

Rizoma vertical, subereto a ereto, com escamas elíptico-lanceoladas, dicromáticas, i.e., região central castanho-clara e bordo castanho-escuro, com a margem denteada, dentes geralmente bífidos, formadas por células de paredes delgadas. Frondes com 0,7-1,6 m compr., indumento da face abaxial da raque, raquíolas, costas e cóstulas, bem como, da base e ao longo de toda a extensão do pecíolo formado por escamas oval-lanceoladas, iguais às do rizoma; lâmina 1-pinado-pinatífida a 2pinado-pinatífida, com 7-12 pares de pinas; pinas basais e medianas oval-lanceoladas, pecioladas, subopostas a alternas, com 5-11 pares de pínulas; pínulas lanceoladas, 
pecioluladas a subsésseis, alternas a opostas; nervuras simples ou furcadas, 3-5 pares por segmento. Soros brevemente curvos e curtos, $0,2-0,5 \mathrm{~cm}$ compr.; indúsio castanho-claro, margem fimbriada.

Material selecionado: Paraná: Tijucas do Sul, Vossoroca, 14/II/1974, $R$. Kummrow 308 (MBM, PACA); Morretes, Estrada da Graciosa, 22/XI/1992, J. Cislinski 229; R. N. Cislinski; M. L. Nowadski (UPCB); Guaratuba, BR 376, 20/XII/ 1992, J. Cislinski 254-255, R. N. Cislinski; M. L. Nowadski (UPCB).

Diplazium rostratum distingue-se das demais espécies estudadas por apresentar as escamas dicromáticas da lâmina e da base do pecíolo, com margens denteadas (projeções geralmente bífidas) (Figura 4-E,F; 5-I). Varia com relação à dissecção da lâmina, podendo ser desde 1-pinado-pinatífida a 2-pinada com as pínulas pinatífidas ou com a margem lobada. D. rostratum é semelhante à $D$. leptocarpon quanto à dissecção da lâmina; porém, D. leptocarpon apresenta as escamas do indumento e da base do pecíolo monocromáticas, com margem denteada, cujas projeções raramente são bífidas. Fée (1869) descreveu no mesmo trabalho, D. remotum, diferindo uma da outra, pelo ápice das pínulas e segmentos. Após comparações das ilustrações e descrições originais das espécies, concluiu-se que, $D$. remotum é sinônimo de $D$. rostratum, optando-se por este binômio por ser o que melhor caracteriza a espécie.

Diplazium rostratum distribui-se nas regiões Sul e Sudeste do Brasil, desde Minas Gerais até Santa Catarina. No Estado do Paraná, a espécie ocorre preferencialmente na Floresta Atlântica, geralmente no interior da mata, próximo a riachos e córregos, podendo ser encontrada também em Floresta Ombrófila Mista (mata de Araucária).

9. Diplazium herbaceum Fée, Cryp. Vasc. Brés. 1: 80, t. 23, f. 1. 1869.

Figura: 2-D, E, F; 5-L; 6-L.

Rizoma horizontal, longo-reptante, com escamas oval-lanceoladas, castanhas, monocromáticas ou quase, de margens denteadas, formadas por células com paredes delgadas. Frondes $0,80-1,32 \mathrm{~m}$ compr., indumento da face abaxial formado por tricomas articulados, esparsos sobre a raque, raquíolas e costas; pecíolo com escamas na base, iguais na forma às do rizoma; lâmina oval-lanceolada, 2-pinado-pinatissecta, com 11-15 pares de pinas; pinas basais e medianas elíptico-lanceoladas, pecioladas, subopostas a alternas, com 8-12 pares de pínulas; pínulas elíptico-lanceoladas, moderado a profundamente pinatissectas, pecioluladas, subopostas a alternas; nervuras simples ou furcadas, com 3-6 pares por segmento. Soros retos a brevemente curvos, 0,2-0,4 cm compr.; indúsio castanho-claro, margem brevemente fimbriada.

Material selecionado: Paraná: Rio Branco do Sul, Itaperuçú, 14/II/1967, L.T. Dombrowski 2.437 (PACA, PKDC); Curitiba, Pedreira Andraus, BR 277, 08/IX/ 1992, J. Cislinski 192; R. N. Cislinski; M. L. Nowadski (UPCB); Lapa, Butiatuvinha, 13/XII/1992, J. Cislinski 243, R.N. Cislsinki; M. L. Nowadski (UPCB).

Dentre as espécies com lâmina 2-pinada, Diplazium herbaceum é facilmente distinta das demais pelo rizoma horizontal, longo-reptante e pelas pínulas pinatissectas. A base das pinas apresenta certa variabilidade com relação ao tamanho e os segmentos também mostraram uma considerável variação quanto à forma (obtusos a 
subagudos) e à margem (crenulada a profundamente lobado-denticulada). D. tamandarei Ros. é muito similar à $D$. herbaceum quanto à dissecção da fronde mas distingue-se desta última pela pubescência da face abaxial sobre a raque, raquíolas e parte das costas e pelo indúsio com a margem conspicuamente fimbriada, além do rizoma ereto.

Diplazium herbaceum apresenta distribuição geográfica conhecida para os estados do Rio de Janeiro, Paraná, Santa Catarina e Rio Grande do Sul. No Paraná, a espécie ocorre em matas de galeria e capões, crescendo geralmente nas orlas de matas, próximo de córregos e riachos, não tendo sido encontrada até o presente na Serra do Mar. Sehnem (1979) apresentou ocorrência semelhante para o Estado de Santa Catarina.

Na sistemática das espécies estudadas, os caracteres julgados importantes por mostrarem-se consistentes foram: arquitetura da fronde, dissecção das pinas e pínulas, escamas da base do pecíolo (margem e paredes celulares) ausência ou presença de indumento (quando presente: tipo e a localização) e margem do indúsio.

A estrutura das escamas da base do pecíolo foi considerada um importante caráter taxonômico, pois apresenta-se variável de espécie para espécie. O mesmo também foi ponderado por Christensen (1931 apud Sledge 1962), Holttum (1940 apud Sledge 1962) e Stolze (1981). As escamas variam no tamanho, cor, forma, espessura das paredes celulares e na margem (Figura 5). O indúsio também apresentou variações na cor (castanho-claros a castanho-escuros) e na margem (de inteira, subinteira, brevemente fimbriada a fimbriada) (Figura 6).

As espécies estudadas são plantas com hábito predominantemente terrestre, porém, Diplazium cf. expansum, D. cristatum e D. ambiguum podem ser eventualmente rupícolas.

Das 11 espécies estudadas para o Estado do Paraná, duas (Diplazium cf. striatum e Diplazium sp.) não foram incluídas na chave, apesar de apresentarem características distintas das demais, por não ter sido analisado material suficiente, uma vez que o grupo apresenta grande variabilidade morfológica. $D$. cf. striatum, já referida para o Estado do Paraná por outros autores, foi identificada a partir do exame de um único espécime (Paraná, Arapoti, Barra Mansa, 20/I/1990, J. T. Motta, 1772 (PKDC)), caracterizado por apresentar a raque pubescente, indumento formado por tricomas linear-filiformes, castanhos; ca. de 7 pares de nervuras predominantemente furcadas e pelo indúsio com a margem subinteira (Figura 6 - D). As referências concernentes à D. striatum mencionam que a espécie apresenta-se variável quanto à intensidade e à localização do indumento, dificultando desta forma a identificação. Para Stolze (1981) a espécie é pubérula ou pelo menos pubescente em seus eixos e para Sehnem (1979) e Tryon \& Stolze (1991), a lâmina varia de glabra a pubescente. $D$. cf. striatum assemelha-se à $D$. ambiguum quanto à dissecção da fronde (espécimes com lâmina 1-pinado-pinatífida) e distingue-se desta última principalmente pela pubescência da face abaxial da raque, raquíolas e costas formado por tricomas e escamas.

Diplazium sp. não pôde ser identificada por insuficiência de material. A espécie caracteriza-se por apresentar as escamas da base do pecíolo subclatradas, com a margem remotamente denteada (Figura 5-J), indumento da face abaxial da raquíola e 
costas formado por tricomas e escamas e pelo indúsio com a margem subinteira (Figura 6-J). Após análise das coleções provenientes dos herbários mencionados anteriormente e da bibliografia, verificou-se que Diplazium sp. é próxima de $D$. hians Kze., quanto ao padrão de dissecção da fronde, indumento e indúsio. Esta espécie foi citada para o Brasil por Tryon \& Stolze (1991). Porém, D. hians apresenta o indumento moderado a abundante, inclusive sobre as cóstulas e soros menores. Como foi encontrado apenas um espécime, torna-se difícil certificar-se da identificação e até mesmo das possíveis variações morfológicas deste táxon.

Quanto à distribuição geográfica das espécies estudadas, foram encontrados táxons com ampla ocorrência para o Estado do Paraná, como Diplazium cristatum e $D$. petersenii e com distribuição restrita: $D$. cf. striatum, $D$. leptocarpon e Diplazium sp. Com exceção de $D$. herbaceum e $D$. cf. expansum, cuja ocorrência foi registrada apenas para as regiões serranas (de Planalto), a maioria das espécies de Diplazium encontra-se preferencialmente na Floresta Atlântica (Serra do Mar), como constatado por Tryon \& Tryon (1982), onde as regiões Sul e Sudeste foram citadas como um dos centros de alta diversidade de espécies, principalmente na Serra do Mar.D. petersenii e D. rostratum também foram encontradas em Florestas Ombrófilas Mistas (matas de Araucárias) (Tabela. 1).

Os táxons que apresentam uma ampla distribuição, foram os que mostraram uma grande variação morfológica quanto à dissecção da lâmina.

Tabela 1. Distribuição Geográfica de Diplazium Sw. no Estado do Paraná

\begin{tabular}{lcccc}
\hline Espécie & Serra do Mar & $1^{\circ}$ Planalto & $2^{\circ}$ Planalto & $3^{\circ}$ Planalto \\
\hline D. plantaginifolium & $\mathrm{XX}$ & & & \\
$\begin{array}{l}\text { D. cristatum } \\
\text { D. petersenii }\end{array}$ & $\mathrm{XX}$ & $\mathrm{XX}$ & $\mathrm{XX}$ & $\mathrm{XX}$ \\
$\begin{array}{l}\text { D. cf. striatum } \\
\text { D. ambiguum }\end{array}$ & $\mathrm{XX}$ & $\mathrm{XX}$ & $\mathrm{XX}$ & $\mathrm{XX}$ \\
$\begin{array}{l}\text { D. turgidum } \\
\text { D. cf. expansum }\end{array}$ & $\mathrm{XX}$ & $\mathrm{XX}$ & & \\
$\begin{array}{l}\text { D. leptocarpon } \\
\text { D. rostratum }\end{array}$ & $\mathrm{XX}$ & $\mathrm{XX}$ & $\mathrm{XX}$ & \\
Diplazium sp. & $\mathrm{XX}$ & $\mathrm{XX}$ & & \\
D. herbaceum & & $\mathrm{XX}$ & & \\
\hline
\end{tabular}

\section{Agradecimentos}

A autora agradece ao Prof. Dr. Jefferson Prado pela orientação e ao CNPq pela bolsa de estudo concedida para a realização desta pesquisa.

\section{Referências bibliográficas}

Angely, J. 1963. Flora Analítica do Paraná. Curitiba. Instituto Paranaense de Botânica. 23: 92-129.

Baker, J. G. 1870. Cyatheaceae et Polypodiaceae, In Martius, C. F. P.. Flora Brasiliensis. 1(2): 307-334. 
Dombrowski, L. T. D. 1972. Coleção de Pteridophytas do Paraná. Araucariana, Ser. Bot. 2: 1-30.

Fée, A. L. A. 1869. Cryptogames vasculaires du Brésil. Part I. Paris, p. 81-82.

Maack, R. 1981. Geografia Física do Estado do Paraná, $2^{2}$ ed.. Rio de Janeiro: J. Olympio.

Proctor, E. R. 1985. Ferns of Jamaica. British Museum (Natural History). London. p. 392-409.

Radford, A. E.; Dickson, W. C.; Massey, R. \& Bell, C. R. 1974. Vascular plant systematics. New York. Hoyer \& Row.

Sehnem, A. 1979. Aspidiáceas in R. Reitz Ed., Flora Ilustrada Catarinense. Herbário Barbosa Rodrigues. Itajai. p. 293-323.

Sledge, W. A. 1962. The Athyrioid ferns of Ceylon. Bull. Brit. Mus. (Nat. Hist.) Bot. 2 (11): 277-329.

Stolze, R. G. 1981. Ferns and ferns allies of Guatemala, Part II - Polypodiaceae. Field. Bot. 6: 182-199.

Tryon, R. M. \& Stolze, R. G. 1991. Pteridophyta of Peru, Part. IV. Dryopteridaceae - 17. Field. Bot. 27: 65-88.

Tryon, R. M. \& Tryon, A. F. 1982. Ferns and allies plants, with special reference to Tropical America. New York. Springer Verlag. 